\title{
Association of Anxiety, Depression, and Somatization with Menstrual Problems among North Korean Women Defectors in South Korea
}

\author{
Hyun Kyoung Kim¹, Hee Sook Kim² ${ }^{\circledR}$, and Seog Ju Kim³ \\ ${ }^{1}$ Department of Nursing, Korea Christian University, Seoul, Republic of Korea \\ ${ }^{2}$ Department of Nursing, Dongnam Health University, Suwon, Republic of Korea \\ ${ }^{3}$ Department of Psychiatry, College of Medicine, Sungkyunkwan University, Samsung Medical Center, Seoul, Republic of Korea
}

Objective North Korean women defectors have suffered from anxiety, depression, and somatization after defection. Also they have had many menstrual problems like amenorrhea. This study was done to identify the correlations of anxiety, depression, and somatization to menstrual problems among North Korean woman defectors in South Korea.

Methods The participants in this study were 126 women from 5 government resettlement centers throughout South Korea. Questionnaires which included State-Trait Anxiety Inventory (STAI), Center for Epidemiological studies-Depression Scale (CED-S), and Symptom Checklist-90-Revised (SCL-90-R) were used to identify anxiety and somatization. Data were collected between June and September, 2012. Results The women reported the following problems; amenorrhea (9.5\%), hypomenorrhea (13.6\%), menorrhagia (19.8\%), polymenorrhea (13.5\%), oligomenorrhea (4.8\%), changes in amount of menstrual discharge (4.0\%), and changes in amount of blood clot (9.5\%). Anxiety $(r=0.20, p=0.002)$, depression $(r=0.25, p=0.005)$, and Somatization $(r=0.35, p<0.001)$ were correlated with number of menstrual problems.

Conclusion The results of this study indicate that mental health services need to be taken into account in interventions for North Korean woman defectors to improve their reproductive health including addressing menstrual problems.

Psychiatry Investig 2017;14(6):727-733

Key Words Anxiety, Depression, Menstruation, North Korean defector, Somatization.

\section{INTRODUCTION}

For political and economic reasons, North Korean defectors started to come to South Korea via third nations in the 1990s. After 2,000, 1,000-2,700 people came to South Korea every year. The total number of defectors from North Korean is now over 20,000. The rate of women among North Korean defectors rapidly increased from $12 \%$ in 1998 to $76 \%$ of the total annual number in 2013 . Over $95 \%$ of women defectors were of reproductive age between 20 to 49 years old. ${ }^{1}$

Received: August 19, 2016 Revised: November 23, 2016

Accepted: December 18, 2016 Available online: August 29, 2017

$\triangle$ Correspondence: Hee Sook Kim, RN, PhD

Department of Nursing, Dongnam Health University, 50 Cheoncheon-ro 74beongil, Jangan-gu, Suwon 16328, Republic of Korea

Tel: +82-31-249-6657, Fax: +82-31-249-6480, E-mail: kimhs02041@hotmail.com

(c) This is an Open Access article distributed under the terms of the Creative Commons Attribution Non-Commercial License (http://creativecommons.org/licenses/bync/4.0) which permits unrestricted non-commercial use, distribution, and reproduction in any medium, provided the original work is properly cited.
North Korean Women Defectors (NKWD) usually suffered from life threatening during their escape. They were exposed to starvation, cold, gun shots, torture, detention, and arrest. Because they were women their risks included unintended marriage with men of the third nations, abortion, sexual abuse, and human trafficking. ${ }^{2}$ Their human rights were infringed that it became a world issue. Health problems were reported during defection ${ }^{3-5}$ and included Post-Traumatic Stress Disorder (PTSD), ${ }^{3,4,6}$ cardiovascular disease, ${ }^{4}$ and malnutrition. ${ }^{5}$

Painful experiences during escape caused anxiety and somatization as mental problems. ${ }^{3,4,6}$ NKWD had a higher prevalence rate of PTSD, anxiety, depression, somatization, and aggressiveness than men defectors. ${ }^{2,3,6}$ The psychological problems had an influence on physical health problems. Anxiety in women can cause multiple and consistent somatic symptoms like pain, abdominal discomfort, reproductive problems, cardiovascular or cerebral symptoms. ${ }^{7}$

Over $70 \%$ of women who experienced the Sichuan earth- 
quake in China had menstrual abnormalities like amenorrhea. ${ }^{8}$ NKWD had anxiety from violence and arrest by police, so they could have somatic symptoms. ${ }^{9}$ Their psychological pain may have had an effect on their menstrual problems. Their mental health problems were reported as anxiety and somatization. ${ }^{3,6}$ The reported menstrual problems of NKWD were amenorrhea, decrease of menstrual duration and amount. ${ }^{10,11}$ Each mental health problem and menstrual problems have been reported separately. However, there was no previous research regarding relationship mental health with menstrual problems of NKWD. Therefore, research on the correlation of anxiety, depression, and somatization on menstrual problems of NKWD is necessary.

NKWD have roles of childbearing and care in the process of their adaptation to the new environment in South Korea. Their reproductive health rights should be supported not only for their wellness but also for the next generation's health. South Korea is responsible to ensure their reproductive health rights as fundamental human rights. Therefore the aim of this study was to identify the menstrual problems of these women as an index of reproductive health, and anxiety and somatization as indicators of psychological health status, and the relationship between menstrual problems and psychological health. The results of this study will provide basic data for interventions to alleviate menstrual problems in NKDW that result from psychological health problems.

The purpose of this study was to identify correlations between anxiety and somatization with menstrual problems among NKWD in South Korea. The goals were identifying 1) general characteristics and menstrual problems, 2) anxiety, depression, and somatization, and 3) correlations of anxiety, depression, and somatization with menstrual problems.

\section{METHODS}

\section{Study design and participants}

This study was a cross sectional research investigation of correlations of anxiety, depression, and somatization with menstrual problems. A convenience sampling was used in 5 Hana centers throughout South Korea. Data were collected from June 1 to September 30, 2012. The research participants were 132 NKWD in South Korea living at 5 Hana centers (government resettlement centers). The calculated sample size was 109 using G* power 3.0.10 program (power=0.90, effect size medium $=0.30$, correlation with two tailed test). ${ }^{12}$ Data were collected from 132 women to compensate for missing data. The final data analysis included 126 women. Of the total 6 were excluded because of incomplete data. Inclusion criteria were 1) age (from menarche to menopause), 2) length of stay in South Korea ( $<10$ years), and 3 ) agreement to partici- pate in the research. Exclusion criteria were 1) past history of reproductive health problems (including uterus myoma, endometriosis, and ovarian mass), 2) present disease, treatment or medication, 3) past history of cancer or hormonal change (including breast cancer, thyroid disease, and hormonal drug use), and 4) past history of diagnosis and treatment for psychological problems).

\section{Ethical consideration}

The Institutional Review Board at a university hospital approved this study (No: 13-005). Trained assistant researchers who passed the proof of education in research ethics collected the data. They explained the purpose of the study, method, time required, confidentiality, a description of the investigator's qualifications and that rejecting participation or withdrawing at any time carried no penalty. After consent to participate was received, the questionnaires were given to the women. An assistant researcher read the questionnaire for women who had problems with vision or fatigue. Time required to complete the questionnaire was 15-20 minutes. Money was given to the women as thanks for participation.

\section{Measurements}

\section{Anxiety}

Anxiety is the subjective emotional response, that ambiguous unpleasant feeling occurring due to unmet psychological need in a risky environment. ${ }^{13}$ Korean version of State Trait Anxiety Inventory (STAI) was used in this study. ${ }^{14}$ The subscales are state anxiety for special circumstance ( 20 items) and trait anxiety for congenital emotional characteristics (20 items). In this study only the state anxiety scale was used. It is 4-point Likert scale ranging from 1 (never) to 4 (always). The range of score is $20-80$. A score over 52 indicates anxiety. ${ }^{14}$ The internal consistency was 0.91 in this study.

\section{Depression}

Depression was measured using Korean version of the Center for Epidemiological studies-Depression Scale (CED-S), ${ }^{15}$ created by the National Institute of Mental Health. ${ }^{16}$ It has 20 items that are rated on a 4-point Likert scale in relation to experiences during the last week. The range of score is $0-60$. The internal consistency was 0.89 in the original research, and 0.87 in this study.

\section{Somatization}

Somatization describes a complex symptom disorder in which various and consistent physical symptoms appear but a clear cause is not apparent. ${ }^{14}$ The checklist used for this study was the Korean version of the Symptom Checklist Somatic (SCL- 
SOM) ${ }^{17}$ from the Symptom Checklist-90-Revised (SCL-90SOM). ${ }^{18}$ SCL-90-SOM is comprised of 90 items which include somatization, interpersonal sensitivity, depression, anxiety, hostility, fear, paranoia, and psychological disease. The SCLSOM has 12 items which ask about physical discomfort. It is a 5-point Likert scale from 0 'never' to 4 'very severe'. The range of the scale is $0-48$. Scores from 19-22 indicate a tendency for somatization, from 23-26 a considerably high level of somatization, and over 27, a very high level of somatization. The internal consistency was 0.94 in this study.

\section{Menstrual problems}

Menstrual problems according to International Federation

Table 1. General characteristics of participants $(N=126)$

\begin{tabular}{|c|c|c|c|c|}
\hline Variables & Categories & $\mathrm{N}(\%)$ & $\mathrm{M}(\mathrm{SD})$ & Range \\
\hline \multirow[t]{3}{*}{ Age (years) } & $19-29$ & $37(29.4)$ & $34.31(8.33)$ & $19-49$ \\
\hline & $30-39$ & $47(37.3)$ & & \\
\hline & $40-49$ & $42(33.3)$ & & \\
\hline \multirow[t]{5}{*}{ Marital status } & Married & $42(33.3)$ & & \\
\hline & Unmarried & $54(42.9)$ & & \\
\hline & Divorced & $15(11.9)$ & & \\
\hline & Widowed & $9(7.2)$ & & \\
\hline & No response & $6(4.7)$ & & \\
\hline \multirow[t]{4}{*}{ Length of education in North Korea (years) } & $5-9$ & $10(7.9)$ & $11.11(1.72)$ & $5-16$ \\
\hline & $10-14$ & $105(83.3)$ & & \\
\hline & $15-19$ & $8(6.3)$ & & \\
\hline & No response & $3(2.4)$ & & \\
\hline \multirow[t]{3}{*}{ Length of stay in South Korea (years) } & $1<$ & $14(11.1)$ & $2.27(1.94)$ & $0-9$ \\
\hline & $1-3$ & $90(71.4)$ & & \\
\hline & $4-9$ & $22(17.5)$ & & \\
\hline \multirow[t]{5}{*}{ Occupation } & No job & $53(42.1)$ & & \\
\hline & Student & $31(24.6)$ & & \\
\hline & Office job & $13(10.3)$ & & \\
\hline & Service job & $10(7.9)$ & & \\
\hline & No response & $19(15.1)$ & & \\
\hline \multirow[t]{5}{*}{ Monthly income (US\$) } & 0 & $73(57.9)$ & & \\
\hline & $<1,000$ & $26(20.6)$ & & \\
\hline & $1,000-2,000$ & $22(17.5)$ & & \\
\hline & $2,001-4,000$ & $1(0.8)$ & & \\
\hline & No response & $6(4.7)$ & & \\
\hline \multirow[t]{5}{*}{ Religion } & No religion & $44(34.9)$ & & \\
\hline & Protestant & $41(32.5)$ & & \\
\hline & Catholic & $2(1.5)$ & & \\
\hline & Buddhist & $4(3.2)$ & & \\
\hline & No response & $35(27.8)$ & & \\
\hline Number returned to North Korea & & & $0.26(0.57)$ & $0-3$ \\
\hline
\end{tabular}

of Gynecology and Obstetrics (FIGO) were classified into period, duration, regularity, and amount of discharge. ${ }^{19}$ According to this classification, the total number of menstrual problems identified in this study was 8 . Problems during the menstrual period were 1 ) amenorrhea (no menstruation $>6$ month), 2) polymenorrhea (period $<20$ days), and 3) oligomenorrhea (period $>40$ days). The duration of menstrual problems was 4 ) hypomenorrhea (duration $<2$ days) and 5) menorrhagia (duration $>7$ days). The problems in menstrual regularity were 6) irregular menstruation. The menstrual problems amount of discharge were 7) change in amount and 8) change in number of blood clot.

US\$: United States Dollar 


\section{Data analysis}

The data were analyzed using the SPSS/WIN 21.0 (IBM Corp., Armonk, NY, USA). Means, standard deviations, and ranges were used to analyze general and menstrual characteristics, anxiety, depression, and somatization level. Pearson correlation coefficients were used to analyze correlations between anxiety, depression, somatization, and total number of menstrual problems.

\section{RESULTS}

\section{General characteristics of the women}

Mean age was 34.31 ( $\mathrm{SD}=8.33$ ) and married women accounted for 33.3\%. Mean residence in South Korea was 2.27 years $(\mathrm{SD}=1.94)$. The majority of the women were unemployed (42.1\%) or students $(24.6 \%)$. Economic status was low, and women reporting no income accounted for $57.9 \%$. The mean number returned to North Korea was $0.26(\mathrm{SD}=0.57)$ (Table 1).

\section{Menstrual characteristics of the women}

The means for menarche and first pregnancy were 16.51 (SD= $2.51)$ and $24.88(\mathrm{SD}=3.35)$ respectively, for gravity and parity, $2.42(\mathrm{SD}=1.40)$ and $1.26(\mathrm{SD}=0.44)$ and for spontaneous and artificial abortion, $1.24(\mathrm{SD}=0.73)$ and $1.58(\mathrm{SD}=1.08)$. The rate for amenorrhea was $9.5 \%$, for polymenorrhea and oligomenorrhea, $13.5 \%$ and $4.8 \%$, and for hypomenorrhea and menorrhagia, $13.6 \%$ and $19.8 \%$. The rate for irregular menstruation was $34.2 \%$ and the rates for change in amount of menstrual

Table 2. Health status and menstrual problems of participants $(\mathrm{N}=126)$

\begin{tabular}{|c|c|c|c|c|c|}
\hline Variables & Categories & & $\mathrm{N}(\%)$ & $\mathrm{M}(\mathrm{SD})$ & Range \\
\hline Gravity & & & & $2.42(1.40)$ & $1-8$ \\
\hline \multirow[t]{2}{*}{ Parity experience } & & Yes & $93(73.8)$ & & \\
\hline & & No & $33(26.2)$ & & \\
\hline First pregnancy (years of age) & & & & $24.88(3.35)$ & $17-37$ \\
\hline \multirow[t]{2}{*}{ Abortion } & & Yes & $69(54.8)$ & $1.07(1.32)$ & $0-8$ \\
\hline & & No & $57(46.8)$ & & \\
\hline \multirow[t]{2}{*}{ Spontaneous abortion } & & Yes & $36(28.6)$ & $1.24(0.73)$ & $0-3$ \\
\hline & & No & $90(71.4)$ & & \\
\hline \multirow[t]{2}{*}{ Artificial abortion } & & Yes & $49(38.9)$ & $1.58(1.08)$ & $0-7$ \\
\hline & & No & $77(61.1)$ & & \\
\hline \multirow[t]{16}{*}{ Menstruation } & Amenorrhea & Yes & $12(9.5)$ & & \\
\hline & & No & $114(90.5)$ & & \\
\hline & Hypomenorrhea & Yes & $17(13.6)$ & & \\
\hline & & No & $109(86.4)$ & & \\
\hline & Menorrhagia & Yes & $25(19.8)$ & & \\
\hline & & No & $101(80.2)$ & & \\
\hline & Polymenorrhea & Yes & $17(13.5)$ & & \\
\hline & & No & $109(86.4)$ & & \\
\hline & Oligomenorrhea & Yes & $6(4.8)$ & & \\
\hline & & No & $120(95.2)$ & & \\
\hline & Irregularity & Yes & $43(34.2)$ & & \\
\hline & & No & $83(65.8)$ & & \\
\hline & Change in amount of menstrual discharge & Yes & $5(4.0)$ & & \\
\hline & & No & $121(96.0)$ & & \\
\hline & Change in amount of menstrual clots & Yes & $12(9.5)$ & & \\
\hline & & No & $114(90.5)$ & & \\
\hline \multirow[t]{6}{*}{ Number of menstrual problems } & & 0 & $36(28.6)$ & $1.61(1.36)$ & $0-5$ \\
\hline & & 1 & $28(22.2)$ & & \\
\hline & & 2 & $24(19.0)$ & & \\
\hline & & 3 & $26(20.6)$ & & \\
\hline & & 4 & $11(8.7)$ & & \\
\hline & & 5 & $1(0.8)$ & & \\
\hline
\end{tabular}


discharge and blood clots were $4.0 \%$ and $9.5 \%$. The total mean number and range of menstrual problems were $1.61(\mathrm{SD}=1.36)$ and 0-5 (Table 2).

\section{Anxiety, depression, and somatization level}

The mean and range for anxiety were $44.56(\mathrm{SD}=11.91)$ and $20-79$. The positive rate of anxiety was $31.0 \%$. The mean and range for depression were $19.94(\mathrm{SD}=12.41)$ and $1-53$. The positive rate of depression was $40.0 \%$. The mean and range for somatization were $24.93(\mathrm{SD}=10.24)$ and $0-48$. The positive rate of somatization was $66.7 \%$ (Table 3 ).

\section{Correlations among anxiety, depression, somatization, and menstrual problems}

Somatization was correlated with anxiety $(r=0.79, \mathrm{p}<0.001)$. Depression was correlated with anxiety $(\mathrm{r}=0.48, \mathrm{p}<0.001)$ and Somatization $(r=0.60, p<0.001)$. The number of menstrual problems was correlated significantly with anxiety $(r=0.20, p=$ $0.002)$, depression $(r=0.25, p=0.005)$, and somatization $(r=0.35$, $\mathrm{p}<0.001$ ) (Table 4).

\section{DISCUSSION}

The results of this study contribute to investigations of anxiety, depression, somatization, and menstrual problems of NKWD. They study show that the number of menstrual problem correlated with anxiety, depression, and somatization among NKWD in South Korea. The women's general characteristics showed that their socioeconomic status was similar to the population of 18,000 NKWD. ${ }^{1}$ The monthly income was under 1,000 US dollars for over $70 \%$ of the women. Un- employed women accounted for $40 \%$ of the total. Over $70 \%$ of the women were in the reproductive age of 30-40 years, so they experienced pregnancy, delivery, and childbearing. They had a double burden of poverty and the labor of caring for their families. They suffered as refugees, women, and mothers. ${ }^{20}$

In this study, the mean number of those returned to North Korea was 0.26 times. They escaped from North Korea and went to third nations like China, Mongolia, Vietnam, and Cambodia, as illegal immigrants. ${ }^{20}$ If they were found by police or the North Korean secret police, they would be forced to return to North Korea. ${ }^{2}$ Their traumatic events can induce to anxiety and stress disorder. ${ }^{21}$

Reproductive health of the women was not good. Their mean menarche was at 16.51 years of age. There have been consistent reports of the late of menarche of North Korean women compared to that of South Korean women at 11-13 years of age. ${ }^{22}$ The percentage of abortion was $54.8 \%$, which is higher than that reported in other research at $38.6 \%$ of NKWD. ${ }^{11}$ In this study, the mean number for spontaneous and artificial abortion was 1.24 and 1.58 respectively. That was 5-7 times higher than South Korean women whose mean number of spontaneous and artificial abortion was 0.24 and $0.24 .{ }^{23}$ The mean number for gravity and parity of the women was 2.42 and 1.26 , which is similar to findings of $1-2$ parity reported in other studies of NKWD. ${ }^{11}$ They were similar to that of South Korean women with a mean of gravity and parity of 2.13 and $1.24 .^{23}$

Amenorrhea was reported as $9.5 \%$ of the women. This result is lower than that of another study which reported 30.5\% of NKWD at 3.08 months after escape. ${ }^{10}$ In this study, the women had lived in South Korea for a mean of 2.27 years, so

Table 3. Level of anxiety, depression, and somatization ( $N=126)$

\begin{tabular}{lcccc}
\hline \multicolumn{1}{c}{ Variable } & Categories (score range) & N (\%) & M (SD) & Range \\
\hline Anxiety (STAI) & Negative (20-51) & $87(69.0)$ & $44.56(11.91)$ & $20-79$ \\
Depression (CES-D) & Positive (52-80) & $39(31.0)$ & & $19.94(12.41)$ \\
& Negative (0-20) & $75(60.0)$ & & $1-53$ \\
Somatization (SCL-SOM) & Positive (21-60) & $51(40.0)$ & $24.93(10.24)$ & $0-48$ \\
& Negative (0-18) & $42(33.3)$ & & \\
\hline
\end{tabular}

STAI: State Trait Anxiety Inventory, CES-D: Center for Epidemiological studies-Depression Scale, SCL-SOM: Symptom Checklist Somatic

Table 4. Correlation coefficients of anxiety, somatization, depression, and number of menstrual problems ( $\mathrm{N}=126)$

\begin{tabular}{|c|c|c|c|c|}
\hline \multirow{2}{*}{ Variables } & Anxiety & Somatization & Depression & Number of menstrual problems \\
\hline & $\mathrm{r}(\mathrm{p})$ & $\mathrm{r}(\mathrm{p})$ & $\mathrm{r}(\mathrm{p})$ & $\mathrm{r}(\mathrm{p})$ \\
\hline Anxiety & 1 & & & \\
\hline Somatization & $0.79(<0.001)^{* * *}$ & 1 & & \\
\hline Depression & $0.48(<0.001)^{* * *}$ & $0.60(<0.001)^{* * *}$ & 1 & \\
\hline Number of menstrual problems & $0.20(0.002)^{* *}$ & $0.25(<0.005)^{* *}$ & $0.35(<0.001)^{* * *}$ & 1 \\
\hline
\end{tabular}

${ }^{*} \mathrm{p}<0.05,{ }^{* *} \mathrm{p}<0.01,{ }^{* * *} \mathrm{p}<0.001$ 
the amenorrhea percentage could be lower than just after defection. However, amenorrhea in these women was 2-4 times the normal percentage $2-5 \%$ of general women. ${ }^{24}$ Hypomenorrhea was reported by $13.6 \%$ of the women. The menstrual duration in NKWD decreased to a mean 0.28 days after defection. ${ }^{10}$ This result is higher than Seo et al. ${ }^{11}$ report that hypomenorrhea was $5.7 \%$ in NKWD. Oligomenorrhea was reported by $4.8 \%$ of the women. This result was coincident with that of menstrual period increase to 8 days after defection reported in another study. ${ }^{10}$

Irregular menstrual cycle was reported by $34.2 \%$ of the women which is a lower proportion compared to $43.3 \%$ found in Yuk et al. ${ }^{10}$ study. It was much higher than the menstrual irregularity (19.2\%) of South Korean women. ${ }^{23}$ Of the women, $4.0 \%$ reported changes in amount of menstrual discharge, lower than the $50.6 \%$ reported in another study. ${ }^{10}$ Of the women, $9.5 \%$ reported changes in the amount of menstrual clots, also lower than the $49.7 \%$ reported by other NKWD. ${ }^{10}$ Blood clot increase is one of the menorrhagia symptoms. ${ }^{25}$ The mean number of menstrual problems was 1.61. Therefore, these women need menstrual problem interventions for promotion of reproductive health.

Psychological health problems of the women were dangerously high. Anxiety level was high. The anxiety positive group whose STAI cut off was over 52 accounted for $31.0 \%$ in this study. Kim et al. ${ }^{6}$ reported that the anxiety positive group was $37.9 \%$ of the NKWD. The positive rate of depression (40.0\%) was lower than result of the other study (52.4\%) in the subject of NKWD. ${ }^{6}$ Depression level of the NKWD was high $(\mathrm{M}=$ 19.94) in the comparison with South Korean middle-aged women $(\mathrm{M}=10.42)$ of the other study. ${ }^{26}$ The mean score for somatization was 24.93 in this study. A cut off of over 19 and the range of 23-26 indicate somatic symptom tendency in the SCL-SOM. ${ }^{15}$ Of the women, $66.7 \%$ were in the positive somatization group. Using the same instruments, another study reported $47.6 \%$ of NKWD were somatization positive, and also $10.0 \%$ of North Korean men defectors. ${ }^{6}$

The China women who experienced the Sichuan earthquake reported a much higher somatization level than that of other studies (75.4\%), possibly because the result found just a short time 9 month after the earthquake. The subjects with menstrual problems in this study was $71.4 \%$ and $76.6 \%$ of Sichuan women have abnormal menstruation. Higher phobic anxiety and somatization Sichuan women have more abnormal menstruation. ${ }^{8}$ Negative mental health affects long term physical health. Signs of somatization in Sichuan women were epimenorrhea, oligomenorrhea, irregular menstruation, hypermenorrhea, amenorrhea, dysmenorrhea, and diet and sleep disturbance. ${ }^{8}$

Chronic PTSD can occur 3 years after traumatic event. ${ }^{27}$ If trauma is strong, PTSD last 10 years. Approximately 50\% of Afghanistan women who experienced war had depression, and PTSD after 10 years from the war. ${ }^{28}$ In this study, there were no differences anxiety, somatization, and menstrual problems according to length of stay in South Korea significantly. One of the possible reason is that traumatic events of NKWD were severe, so menstrual problems and somatization prolonged. ${ }^{26}$ Forensic science investigators have PTSD to 10 years because they witness shocking scenes like suicide or homicide, moreover there was no differences of traumatic stress according to length of career. ${ }^{29}$ The other reason of poor mental and physical health was adaptation stress after defection. ${ }^{30}$

Psychological problem of somatization was correlated with menstrual problems in this study $(\mathrm{r}=0.25)$. Blood bradykinin is related anxiety and it causes somatization. ${ }^{31}$ The high level of blood bradykinin enlarges the blood vessels, releases prostaglandin, resulting in menstrual problems like pelvic pain and irregular menstruation. ${ }^{30}$ Pain perception is related to somatization. Higher somatization levels were related to more menstrual symptoms reported in a research related to Arab women. Cultural adaptation stress as Muslim in Israel resulted in menstrual discomfort and pelvic pain. ${ }^{32}$ Iran adolescents with premenstrual syndrome were taken stress management intervention and their somatization and premenstrual syndrome were decreased significantly, but depression and anxiety level were not decreased. ${ }^{33}$ Higher anxiety level was correlated with higher somatization level $(r=0.79)$ in this study. Mental problems like anxiety, phobia, and PTSD have been reported to be correlated with physical problems of NKWD. ${ }^{2-4,6,30}$

Psychological stress affects other physiologic symptoms, but in NKWD it was easy to overlook their somatic symptoms, because the neurobiological mechanism was not clear. They would not see a psychiatrist because they didn't know the cause of the physical symptoms. ${ }^{7}$ Furthermore their responsibility for health was low and they lacked resources like time, money, and information. ${ }^{34}$ The high self-efficacy and perceived competency level of Arab women was found to be related to low menstrual problems. ${ }^{32}$ Therefore, health professionals need to help these women improve health promotion behavior. ${ }^{35}$ Empowerment programs for NKWD may help to reduce their menstrual problems. As this study only included 126 women from 5 adaptation centers, care should be taken in generalizing the results to the total population of NKWD.

In this study, a cross sectional research design was used to identify the correlations of anxiety, depression, and somatization with menstrual problems. The results of this study revealed that psychological and reproductive health conditions of NKWD in South Korea were associated with somatization, depression, and menstrual problems. Because of the low status of these women they are in urgent need of help from health 
professionals. The level of anxiety, somatization, depression, and menstrual problems was high. The results of this study indicate aspects of health circumstances that provide help for NKWD who have overcome painful experiences. Health professionals should understand and endeavor to promote their health status and that of the next generation because these women are of reproductive age. This study was performed with 126 subjects at 5 adaptation centers. Therefore, the present study had a limitation about generalization problems of expansion and interpretation into total NKWD. We suggest that health intervention programs should be developed to promote the psychological and reproductive health of NKWD.

\section{REFERENCES}

1. Ministry of Unification. Policy of North Korea Defectors. Seoul: Ministry of Unification. 2014. http://www.unikorea.go.kr /index.do?menu Cd=DOM_000000105006006000. Accessed 21 January, 2014.

2. Jeon WT, Hong CH, Lee CH, Kim DK, Han M, Min SK. Correlation between traumatic events and posttraumatic stress disorder among North Korean defectors in South Korea. J Trauma Stress 2005;18:147154.

3. Shin G, Lee SJ. Mental health and PTSD in female North Korean refugees. Health Care Women Int 2015;36:409-423.

4. Song BA, Yoo SY, Kang HY, Byeon SH, Shin SH, Hwang EJ, et al. Posttraumatic stress disorder, depression, and heart-rate variability among North Korean Defectors. Psychiatry Investig 2011;8:297-304.

5. Choi SK, Park SM, Joung H. Still life with less: North Korean young adult defectors in South Korea show continued poor nutrition and physique. Nutr Res Pract 2010;4:136-141.

6. Kim HH, Lee YJ, Kim HK, Kim JE, Kim SJ, Bae SM, et al. Prevalence and correlates of psychiatric symptoms in North Korean defectors. Psychiatry Investig 2011;8:179-185.

7. Fava G, Fabbri S, Sirr L, Wis TN. Psychological factors affecting medical condition: a new proposal for DSM-V. Psychosomatics 2007;48: 103-111.

8. Liu X, Yang Y, Yuan P, Zhang X, Han Y, Cao Y, et al. A study of the relationship between mental health and menstrual abnormalities in female middle school students from post-earthquake Wenchuan. Biosci Trends 2010;4:4-8.

9. Park JR, Kang DW. A study on female North Korean defectors: trends, controversial issues, and tasks. North Korean Stud Rev 2011;15:1-24.

10. Yuk SS, Kim YS, Lim EM. Study on the variable factors connected with stress affecting menstrual patterns of the North Korean female defectors. J Oriental Obstet Gynecol 2004;17:174-185.

11. Seo JY, Yuk SS, Kim YS, Lim EM. A study on the menarche and the menstrual pattern of the North Korean women. J Oriental Obstet Gynecol 2004;17:186-195.

12. Faul F, Erdfelder E, Lang AG, Buchner A. G*Power 3: a flexible statistical power analysis program for the social, behavioral, and biomedical sciences. Behav Res Methods 2007;39:175-191.

13. Spielberger CD, Gorsuch RL, Lushene RE. Manual for the State-Trait Anxiety Inventory. Palo Alto, CA: Consulting Psychologist Press; 1970.

14. Hahn DW, Lee CH, Chon KK. Korean adaptation of Spielberger's STAI (K-STAI). Korean J Health Psychol 1996;1:1-14.

15. Radloff LS. The CES-D scale: a self-report depression scale for research in the general population. Appl Psychol Meas 1977;1:385-401.

16. Shin SC, Kim MK, Yun KS, Kim JH, Lee MS, Moon SJ, et al. The Cen- ter Epidemiologic Studies-Depression scale (CES-D): its use in Korea. J Korean Neuropsychiatr Assoc 1990;30:752-767.

17. Derogatis LR, Cleary PA. Confirmation of the dimensional structure of the SCL-90: a study in construct validation. J Clin Psychol 1997;33:981989.

18. Kim KI, Kim JW, Won HT. Implementational Direction for Checklist90-Revision (SCL-90-R). Seoul: Chungang Aptitude Publishing Co.; 2012.

19. Munro MG, Critchley HO, Fraser IS. The FIGO systems for nomenclature and classification of causes of abnormal uterine bleeding in the reproductive years: who needs them? Am J Obstet Gynecol 2012;207:259265.

20. Park JR, Kang DW. A study on the marriage and family relationships of female North Korean defectors from a feminist perspective: with a focus on changes to individual levels of acculturation in a migration process. Soc Sci Stud 2011;35:39-63.

21. Min SK. Divided countries, divided mind 1: psycho-social issues in adaptation problems of North Korean defectors. Psychiatry Investig 2008; 5:1-13.

22. Kim YI, Lee EH, Jeon GE, Choi SJ. A study on coping styles for dysmenorrhea and affecting factors in middle school students. J Korean Acad Community Health Nurs 2013;24:264-272.

23. Kim SK, Kim YK, Kim HR, Park JS, Son CG, Choi YJ, et al. The 2012 National Survey on Fertility, Family Health \& Welfare in Korea. Seoul: Korea Institute for Health and Social Affairs; 2012.

24. Chartrand D, Chatfield SJ. A critical review of the prevalence of secondary amenorrhea in ballet dancers. J Dance Med Sci 2005;9:74-80.

25. Garside R, Britten N, Stein K. The experience of heavy menstrual bleeding: a systematic review and meta-ethnography of qualitative studies. J Adv Nurs 2008;63:550-562.

26. Jo HK, Kim JH. Factors affecting suicidal ideation among middle-aged Korean women in an urban-rural province. Arch Psychiatr Nur 2016;30: 539-543.

27. Hong CY, Yoo JJ, Cho YA, Eom J, Ku HJ, Seo SW, et al. A 3-year followup study of posttraumatic stress disorder among North Korean defectors. J Korean Neuropsychiatr Assoc 2006;45:49-56.

28. Shin SM, Kim HJ, Liw L, Kim S. Depression and PTSD in Pashtun women in Kandahar, Afghanistan. Asian Nurs Res (Korean Soc Nurs Sci) 2009;3:90-98.

29. Yoo YS, Cho OH, Cha KS, Boo YJ. Factors influencing post-traumatic stress in Korean forensic science investigators. Asian Nurs Res (Korean Soc Nurs Sci) 2013;7:136-141.

30. Jeon WT, Eom JS, Min SK. A 7-year follow-up study on the mental health of North Korean defectors in South Korea. J Trauma Stress 2013; 26:158-164.

31. Fukuda K. Somatization disorder and bradykinin. Psychiatry Clin Neurosci 2003;57:609.

32. Goldstein-Ferber S, Granot M. The association between somatization and perceived ability: roles in dysmenorrhea among Israeli Arab adolescents. Psychosom Med 2006;68:136-142.

33. Taghizadeh Z, Shirmohammadi M, Feizi M, Arbabi M. The effect of cognitive behavioural psycho-education on premenstrual syndrome and related symptoms. J Psychiatr Ment Health Nurs 2013;20:705-713.

34. Wang BR, Kwon YD, Jeon WT, Noh JW. Factors associated with the frequency of physician visits among North Korean defectors residing in South Korea: a cross-sectional study. BMC Health Serv Res 2015;15:90.

35. Choe MA, Lee M, Choi JA, Shin G. Health knowledge, health promoting behavior and factors influencing health promoting behavior of North Korean defectors in South Korea. J Korean Acad Nurs 2012;42: 622-631. 